\title{
Ecobairro - perspectivas e desafios do projeto urbano
}

Ecological Neighborhood - perspectives and challenges of urban design

Ecobairro - perspectivas y desafíos del proyecto urbano

Franciele Cavalheiro Novack

Acadêmica do curso de graduação da UNIVAG - Centro Universitário, e graduada em Ciências Biológicas na UNIVAG - Centro Universitário, Brasil. frannovack@hotmail.com

Jeane Aparecida Rombi de Godoy Rosin Professora Doutora, UNIVAG, Brasil. urbanista.jeane@gmai.com 


\section{RESUMO}

O planejamento urbano, sobretudo na criação de novos modelos voltados ao loteamento residencial, deve primar pelos padrões de excelência em infraestrutura, visando garantir qualidade espacial e consequentemente qualidade de vida a seus usuários. Frente a tais premissas, torna-se necessário que o poder público adote estratégias para orientação dos novos parcelamentos do solo e busque também qualificação dos quadros técnicos responsáveis pelo licenciamento e fiscalização de todo o processo que envolva a política de desenvolvimento urbano no município e seus desdobramentos. No âmbito dessa questão, surge a necessidade de novas alternativas que possam contribuir para a busca da sustentabilidade urbana, para a qual o processo de produção das cidades, em específico, o parcelamento do solo é fundamental. Desse modo, o presente trabalho tem por objetivo discutir os desafios e perspectivas que envolvem a elaboração de uma proposta para implantação de um loteamento voltado à habitação de interesse social a partir dos conceitos que norteiam o "Ecobairro", onde são considerados os princípios da sustentabilidade e aplicação das tecnologias da infraestrutura verde. A proposta busca beneficiar as famílias de baixa renda, visando alcançar a melhoria da qualidade de vida, com a oferta de espaços verdes públicos adequados ao uso de suas funções, além de infraestrutura adequada. Em razão de suas amplas e importantes funções, a proposta elaborada deverá possibilitar a correta interação entre o meio ambiente e o meio urbano, através da incorporação dos princípios da sustentabilidade - aqueles que forem possíveis e adaptáveis a realidade local, assim como das técnicas da infraestrutura verde.

PALAVRAS-CHAVE: Ecobairro, sustentabilidade, Infraestrutura Verde.

\section{ABSTRACT}

Urban planning, especially in the creation of new models aimed at residential subdivision, should be based on the standards of excellence in infrastructure, aiming to guarantee spatial quality and consequently quality of life for its users. Faced with such premises, it is necessary that the public power adopt strategies to guide the new land parceling and also seek qualification of the technical staff responsible for licensing and supervision of the whole process that involves the urban development policy in the municipality and its unfolding. Within the scope of this question, the need arises for new alternatives that can contribute to the search for urban sustainability, for which the production process of the cities, in particular, the parceling of the soil is fundamental. Thus, the present work aims to discuss the challenges and perspectives that involve the elaboration of a proposal for the implementation of a subdivision aimed at housing of social interest based on the concepts that guide the "Ecobairro", where the principles of sustainability are considered and application of green infrastructure technologies. The proposal seeks to benefit low income families, aiming at improving the quality of life, with the provision of public green spaces suitable for the use of their functions, as well as adequate infrastructure. Because of its broad and important functions, the proposal should enable the correct interaction between the environment and the urban environment, through the incorporation of the principles of sustainability - those that are possible and adaptable to the local reality, as well as of the green Infrastructure.

KEYWORDS: Ecological Neighborhood, sustainability, Green Infrastructure.

\section{RESUMEN}

La planificación urbana, sobre todo en la creación de nuevos modelos orientados a la urbanización residencial, debe primar por los estándares de excelencia en infraestructura, buscando garantizar calidad espacial y consecuentemente calidad de vida a sus usuarios. Frente a tales premisas, es necesario que el poder público adopte estrategias para la orientación de los nuevos parcelamientos del suelo y busque también la calificación de los cuadros técnicos responsables de la concesión de licencias y fiscalización de todo el proceso que involucra la política de desarrollo urbano en el municipio y sus desdoblamientos. En el marco de esta cuestión surge la necesidad de nuevas alternativas que puedan contribuir a la búsqueda de la sostenibilidad urbana, para la cual el proceso de producción de las ciudades, en concreto, el parcelamiento del suelo es fundamental. De este modo, el presente trabajo tiene por objetivo discutir los desafíos y perspectivas que involucran la elaboración de una propuesta para implantación de un loteamiento volcado a la vivienda de interés social a partir de los conceptos que orientan el "Ecobair", donde se consideran los principios de la sostenibilidad y la aplicación de las tecnologías de la infraestructura verde. La propuesta busca beneficiar a las familias de bajos ingresos, buscando alcanzar la mejora de la calidad de vida, con la oferta de espacios verdes públicos adecuados al uso de sus funciones, además de infraestructura adecuada. En razón de sus amplias e importantes funciones, la propuesta elaborada deberá posibilitar la correcta interacción entre el medio ambiente y el medio urbano, a través de la incorporación de los principios de la sostenibilidad - los que sean posibles y adaptables a la realidad local, así como a las técnicas de la infraestructura verde.

PALABRAS CLAVE: Ecobarrio, Sostenibilidad, Infraestructura Verde. 


\section{INTRODUÇÃO}

Com o acelerado crescimento das cidades, cada vez mais se faz necessário planejamento urbano na criação de novos loteamentos, que venham a suprir a demanda habitacional com infraestrutura adequada.

A busca de novas estratégias que proporcionem melhoria na qualidade de vida da população e que auxiliem na preservação do meio ambiente é de extrema importância, aliado a implantação de novas políticas públicas que efetivamente proporcionem um diferencial na estrutura urbana e na relação do urbano com o meio ambiente.

Este trabalho visa a elaboração de uma proposta para implantação de um loteamento voltado à habitação de interesse social considerando o conceito de "Ecobairro", a partir dos princípios da sustentabilidade e a aplicação das tecnologias da infraestrutura verde.

A realização de intervenções urbanas e implantação de novos loteamentos em atendimento à uma das demandas básicas da população, a moradia, é primordial, diante do déficit habitacional de aproximadamente 30 mil moradias, conforme o último levantamento da Secretaria de Habitação e Regularização Fundiária de Cuiabá em 2015.

A melhoria nos projetos de loteamentos é imprescindível, frente aos problemas apresentados nos loteamentos atualmente implantados, como baixa qualidade construtiva e escassos ambientes de lazer, situação precária da infraestrutura e dos projetos habitacionais ofertados, além da pouca importância dada aos recursos naturais existentes, o que justifica a implantação de um Ecobairro, que traga uma nova perspectiva para a solução destes problemas.

Em 2008 o Instituto Brasileiro de Geografia e Estatística - IBGE divulgou a Pesquisa Nacional de Saneamento Básico, que teve por objetivo investigar as condições do saneamento básico do país junto às prefeituras municipais e empresas contratadas para a prestação desses serviços nos 5.565 municípios existentes na data de referência da pesquisa.

O estado de Mato Grosso possui 141 municípios e segundo a pesquisa realizada pelo IBGE (2000-2008), todos possuíam algum tipo de serviço de saneamento básico em 2008, sendo 98\% dos municípios com rede geral de distribuição de água, 19\% dos municípios com rede coletora de esgoto, $100 \%$ dos municípios com manejo de resíduos sólidos e $69 \%$ dos municípios com manejo de águas pluviais.

Ainda segundo a pesquisa, dos 27 municípios de Mato Grosso que possuíam o serviço de esgotamento sanitário, apenas 15 (55\%) possuíam legislação municipal que exigia a aprovação e implantação deste sistema para os loteamentos novos, dos 98 municípios que possuíam o serviço de manejo de águas pluviais, apenas 38 (39\%) possuíam legislação municipal que exigia a aprovação e implantação deste sistema para os loteamentos novos, e dos 139 municípios que possuíam o serviço de abastecimento de água por rede geral de distribuição, 68 (49\%) possuíam legislação municipal que exigia a aprovação e implantação deste sistema para os loteamentos novos.

Todos estes dados evidenciam que não havia na época a exigência municipal para a implantação de novos loteamentos com todas as condições de saneamento básico, o que pode ter resultado em inúmeros loteamentos com baixa qualidade sanitária e de infraestrutura. 


\begin{abstract}
condições adequadas de abastecimento de água potável e de manejo de resíduos sólidos, o déficit ainda é bastante significativo em todos os componentes do saneamento básico e representa milhões de pessoas vivendo em ambientes insalubres e expostos a diversos riscos que podem comprometer a sua saúde. Em uma perspectiva histórica, as políticas públicas não foram capazes de propiciar a universalização do acesso às soluções e aos serviços públicos de saneamento básico de qualidade, que teriam contribuído para melhorar as condições de vida desse contingente populacional, reduzindo as desigualdades sociais, e a qualidade ambiental do País. (BRASIL, 2013)
\end{abstract}

Assim como ocorreu no passado, ainda hoje muitas cidades enfrentam problemas como: de saneamento básico, má gestão dos recursos existentes, ausência de políticas públicas voltadas para o bem social, além de falta de planejamento, estruturação e organização da malha urbana.

\title{
2. OBJETIVOS
}

Implantar um loteamento que se torne uma referência, podendo alterar o modo de vida da população, além de transformar a proposta em uma política pública e melhorar a infraestrutura e conceito dos loteamentos de interesse social.

Beneficiar as famílias de baixa renda, melhorando a qualidade de vida deste público com a implantação de mais espaços verdes e recreativos, além de infraestrutura adequada nos loteamentos destinados à estas famílias, propiciando locais agradáveis de se viver e uma cidade melhor.

\section{METODOLOGIA}

Foram realizadas pesquisas bibliográfica e documental, onde os dados foram analisados e serviram de base para a elaboração da proposta do projeto do "Ecobairro", que abrangeu alguns aspectos voltados à sustentabilidade e à infraestrutura verde, associado à sua dinâmica e funcionalidade.

No projeto buscou-se inserir elementos que além de funcionais, se sustentassem com o passar do tempo e que fossem se materializando paralelamente as intervenções do poder público e da população residente.

\section{RESULTADOS}

Um tema que tem sido abordado para a melhoria das cidades é a implantação de Ecobairros, que seria um espaço urbano concebido com diretrizes voltadas para o equilíbrio entre o ambiente natural e urbano, com espaços verdes, proporcionando bem estar e qualidade de vida aos moradores, de forma sustentável, através da economia de energia, de água e correta destinação de resíduos, com espaços e equipamentos para o lazer e interação social, além de estar conectado aos diversos setores da cidade, facilitando a mobilidade e as atividades diárias das pessoas, como as de estudo, trabalho e lazer.

Um ecobairro é uma forma de ocupação do espaço que leva em consideração o solo 


\begin{abstract}
como um bem raro e não renovável e desconsidera as valorizações de curto prazo em decorrências de oportunidades econômicas e fundiárias. O ecobairro deve estar apoiado nos recursos locais e também levar em consideração as grandes questões do planeta, a fim de melhorar a qualidade de vida de seus habitantes e usuários, além de contribuir com a sustentabilidade da cidade através da integração deste com o seu entorno de forma a este não se constituir em um reduto tanto para famílias mais pobres como para as mais favorecidas. (AZEVEDO, 2015)
\end{abstract}

A implantação de Ecobairros é muito importante, tanto para a cidade, quanto para o meio ambiente e as pessoas, pois traz muitos benefícios em prol de todas as esferas.

Alguns princípios da sustentabilidade e da infraestrutura verde são essenciais na implantação dos Ecobairros, portanto foi necessário analisá-los e buscar implantar os que se apresentaram mais viáveis e duradouros.

De acordo com Andrade e Romero (2004), alguns princípios da sustentabilidade são primordiais para a implantação de um loteamento sustentável, dentre eles alguns foram utilizados no projeto conforme relacionado no Quadro 1.

\title{
Quadro 1 - Princípios da Sustentabilidade utilizados no projeto
}

\begin{tabular}{|l|l|}
\hline Princípios da Sustentabilidade & \multicolumn{1}{|c|}{ Finalidade e forma de utilização no projeto } \\
\hline Mobilidade Sustentável & $\begin{array}{l}\text { Propiciar aos moradores vias alternativas e seguras para seu deslocamento, } \\
\text { como ciclovias, vias iluminadas e sinalizadas. }\end{array}$ \\
\hline $\begin{array}{l}\text { Revitalização Urbana e Sentido } \\
\text { de Vizinhança }\end{array}$ & $\begin{array}{l}\text { Implantação de espaços públicos que propiciem encontros, reuniões e } \\
\text { trabalhos conjuntos, integrando o centro das atividades a outras regiões. }\end{array}$ \\
\hline Proteção Ecológica & $\begin{array}{l}\text { Implantação de parques, reserva de áreas preservadas mantendo um } \\
\text { corredor ecológico, arborização das praças e ruas com a faixa vegetada, } \\
\text { hortas, pomar e jardins. }\end{array}$ \\
\hline Drenagem & $\begin{array}{l}\text { Manter o ciclo hidrológico, melhorar o microclima local e efeitos da seca, } \\
\text { através de pavimentos permeáveis, biovaletas, jardins de chuva e bastante } \\
\text { áreas verdes permeáveis. }\end{array}$ \\
\hline Gestão Integrada da Água & $\begin{array}{l}\text { Reaproveitamento das águas pluviais, com a instalação de jardins de chuva } \\
\text { e biovaletas. }\end{array}$ \\
\hline Política dos 3R's & $\begin{array}{l}\text { Reaproveitamento do lixo produzido no bairro, através da reciclagem e } \\
\text { compostagem. }\end{array}$ \\
\hline Energia Solar & $\begin{array}{l}\text { Utilização de luminárias com energia solar, para melhor aproveitamento } \\
\text { energético. }\end{array}$ \\
\hline
\end{tabular}

Fonte: Andrade e Romero (2004)

Brandão e Crespo (2016) trazem algumas técnicas de infraestruturas verdes que estão sendo utilizadas nos loteamentos sustentáveis. No Quadro 2 estão algumas das infraestruturas verdes utilizadas no projeto. 


\section{Periódica Eletrônica}

\section{Fórum Ambiental}

Quadro 2-Infraestruturas Verde

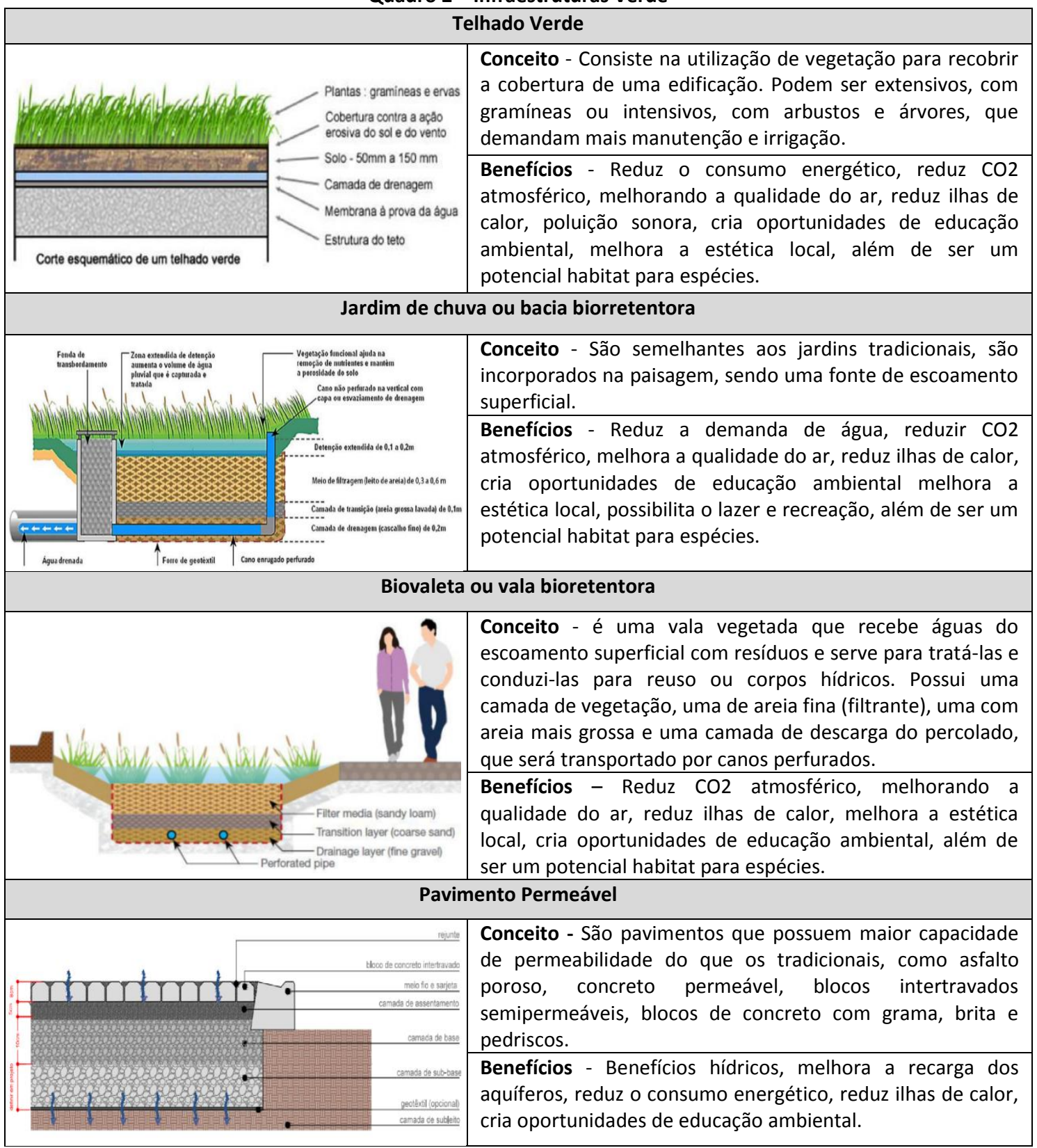

Fonte: Brandão e Crespo (2016)

A área destinada para o loteamento, objeto de estudo, tem aproximadamente $102.000 \mathrm{~m}^{2}$, e está localizada na região do Jardim Imperial em Cuiabá-MT (Figura 1).

A área foi escolhida por estar em uma região que vem tendo um bom desenvolvimento social e possui uma boa infraestrutura comercial e educacional para atender a região, mas que ainda apresenta inúmeros vazios urbanos, tendo um grande potencial para o desenvolvimento de um Ecobairro sustentável para famílias de baixa renda. 


\section{Periódica Eletronica}

\section{Fórum Ambiental}

Volume 14, Número 2, 2018

da Alta Paulista

ISSN 1980-0827

Figura 1 - Área de estudo

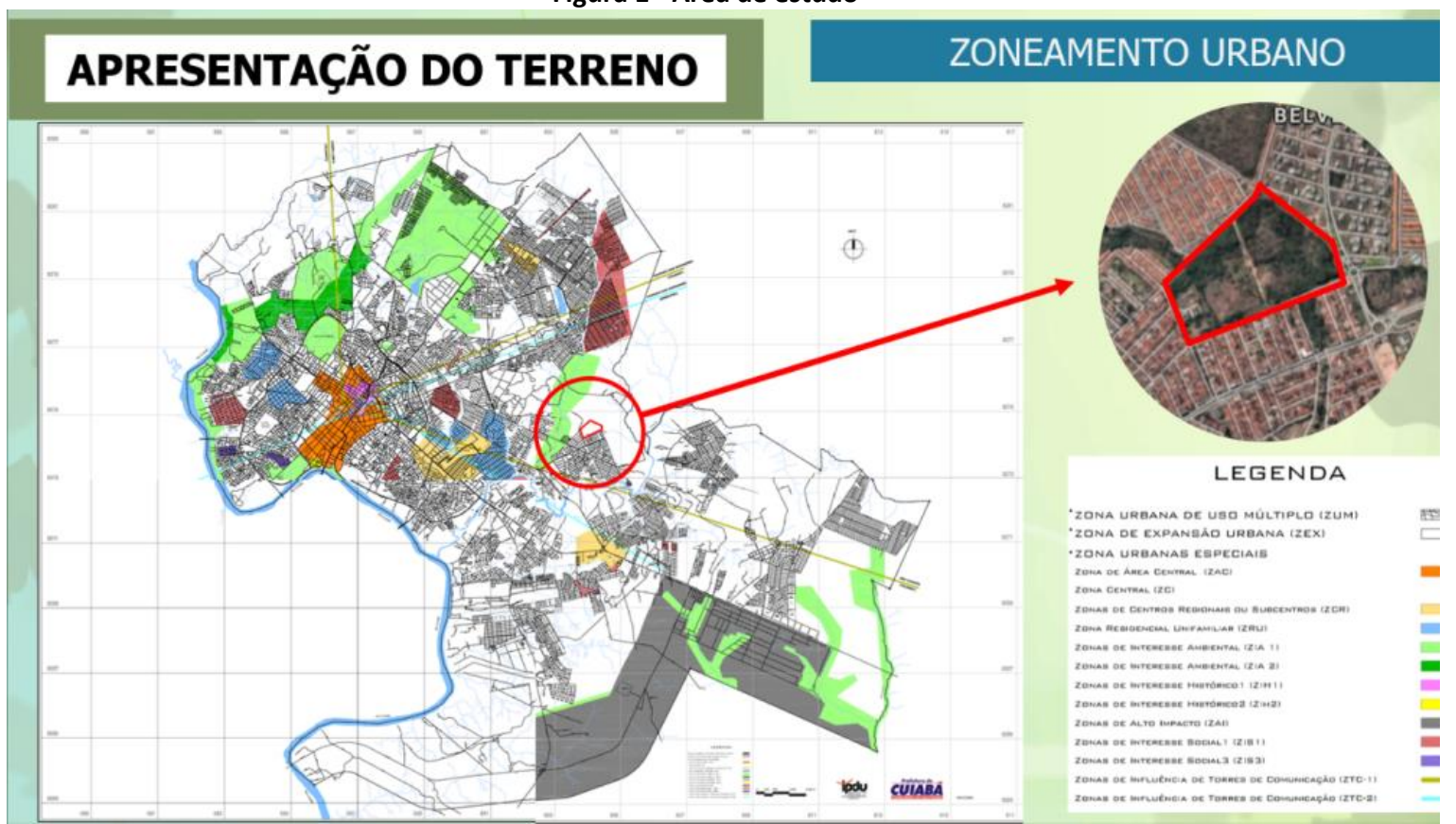

Fonte: Lei complementar no 389 do município de Cuiabá, de 03 de novembro de 2015.

De acordo com a Lei Complementar no 389/2015, que trata do Uso e Ocupação do Solo no município de Cuiabá, o terreno está classificado como ZUM - Zona Urbana de Uso Múltiplo, Categoria de Uso de Médio Impacto - Uso residencial.

Os espaços públicos são essenciais para melhorar a qualidade de vida das pessoas e propiciar ambientes agradáveis e de interação social entre as diversas classes.

Na região há carência de espaços públicos, praças e parques, onde o projeto proposto poderia vir a atender esta demanda existente no local.

Na Figura 2 temos uma imagem do entorno da área destinada para o loteamento, onde pode se observar a ausência de calçada e pouca arborização.

Há uma praça próxima ao terreno do loteamento (Figura 3) que não possui espaços e equipamentos adequados para o lazer, e também é pouco arborizado, o que dificulta a permanência ou uso do local durante o dia, devido ao intenso calor.

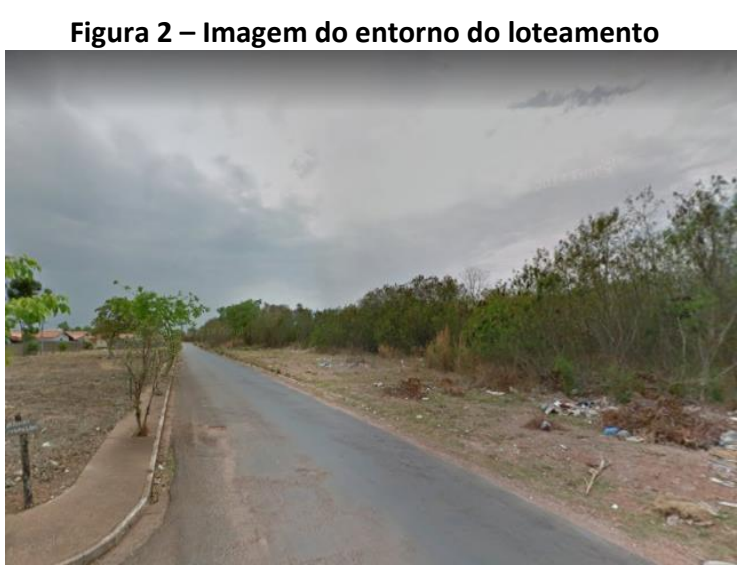

Fonte: Google maps

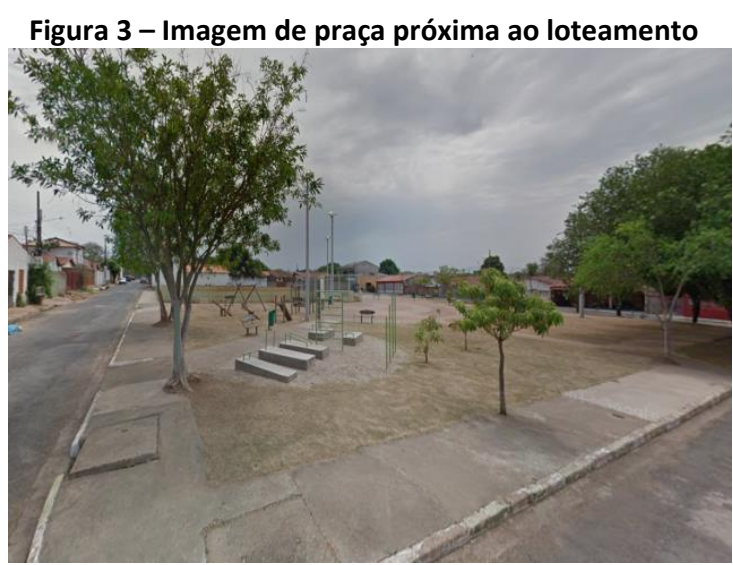

Fonte: Google maps 


\section{Periódica Eletrônica}

\section{Fórum Ambiental}

Volume 14, Número 2, 2018

ISSN 1980-0827

\section{da Alta Paulista}

O loteamento será implantado em uma área periférica, porém mais próximo do centro do que outros loteamentos destinados à esta finalidade.

A área é alimentada por uma via coletora ${ }^{1}$ e possui vias principais $^{2}$ e estruturais ${ }^{3}$ muito próximas, conforme Figura 4, o que permite uma boa mobilidade na região e no loteamento a ser implantado.

Figura 4 - Hierarquia viária

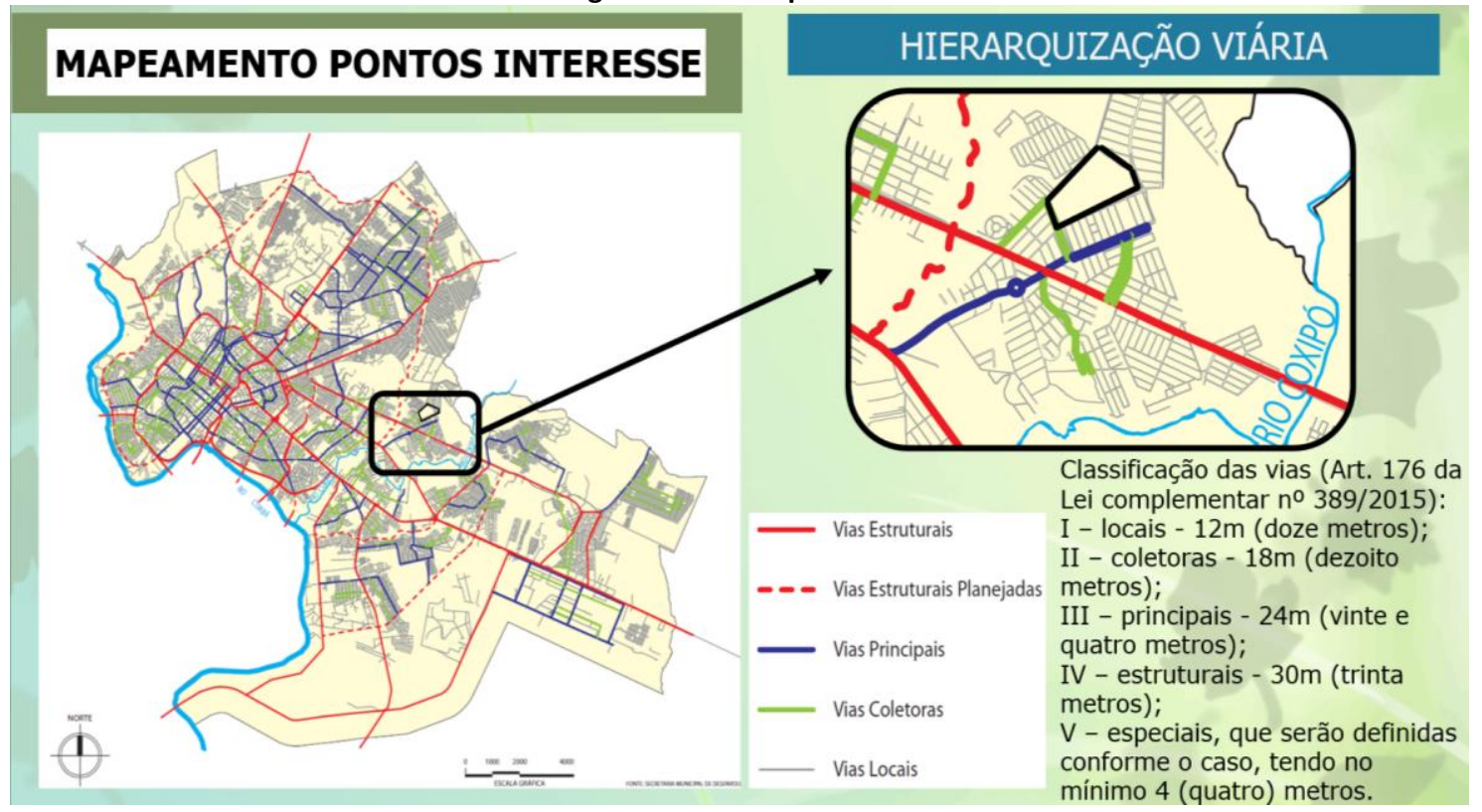

Fonte: Perfil Socioeconômico de Cuiabá, Volume V (2012)

Inúmeros problemas são encontrados em diversos loteamentos implantados em Cuiabá-MT, os quais podem servir de base para implementar melhorias nos novos loteamentos. Na Tabela 3 foram destacados alguns destes problemas identificados no entorno da área de estudo, além das potencialidades que podem auxiliar e melhorar o planejamento de implantação do Ecobairro na região.

Tabela 3 - Problemas e potencialidades

\begin{tabular}{ll}
\hline \multicolumn{1}{c}{ Problemas } & \multicolumn{1}{c}{ Potencialidades } \\
\hline Poucas praças arborizadas e espaços de lazer & Densidade demográfica média-baixa \\
\hline Ausência de ciclovias & Rede viária próxima \\
\hline Poucos espaços para práticas esportivas & $\begin{array}{l}\text { Rede de saúde e educação municipal e estadual } \\
\text { próximas }\end{array}$ \\
\hline Loteamentos destinados à habitação social em lugares & $\begin{array}{l}\text { Sistema de esgoto e abastecimento de água } \\
\text { presente na região }\end{array}$ \\
\hline distantes e com pouca ou nenhuma infraestrutura & $\begin{array}{l}\text { Região com bom desenvolvimento habitacional e } \\
\text { Atendimento de esgoto e água deficitária nos }\end{array}$ \\
loteamentos mais afastados &
\end{tabular}

Fonte: Elaborado pela autora.

Algumas alternativas foram propostas para o alcance dos objetivos do projeto como:

${ }^{1}$ Via coletora: Possui $18 m$ (dezoito metros), conforme Art. 176 da Lei complementar no 389 , de 03 de novembro de 2015.

${ }^{2}$ Via principal: Possui $24 m$ (vinte e quatro metros), conforme Art. 176 da Lei complementar $n$ 은 389, de 03 de novembro de 2015.

${ }^{3}$ Via estrutural: Possui 30m (trinta metros), conforme Art. 176 da Lei complementar no 389, de 03 de novembro de 2015. 


\section{Periódica Eletrônica}

\section{Fórum Ambiental}

Volume 14, Número 2, 2018

ISSN 1980-0827

\section{da Alia Paulista}

- Implantação de calçadas largas e acessíveis com faixas verdes para sombreamento;

- Implantação de ciclovias;

- Construção de praças com espaços adequados e equipamentos para atividades de lazer e esporte;

- Melhoria da distribuição espacial dos terrenos com acesso aos espaços públicos.

O loteamento foi projetado baseado nos princípios da sustentabilidade e infraestrutura verde, sendo que a manutenção e preservação de áreas verdes já existentes e a implantação de praças foram priorizadas, pois são pontos muito relevantes em um Ecobairro.

$\mathrm{Na}$ Figura 6 temos algumas alternativas da infraestrutura verde empregadas no projeto, relacionadas ao meio ambiente que trazem benefícios tanto para o ambiente natural, quanto para o ambiente urbano e social.

Figura 6 - Alternativas da Infraestrutura Verde

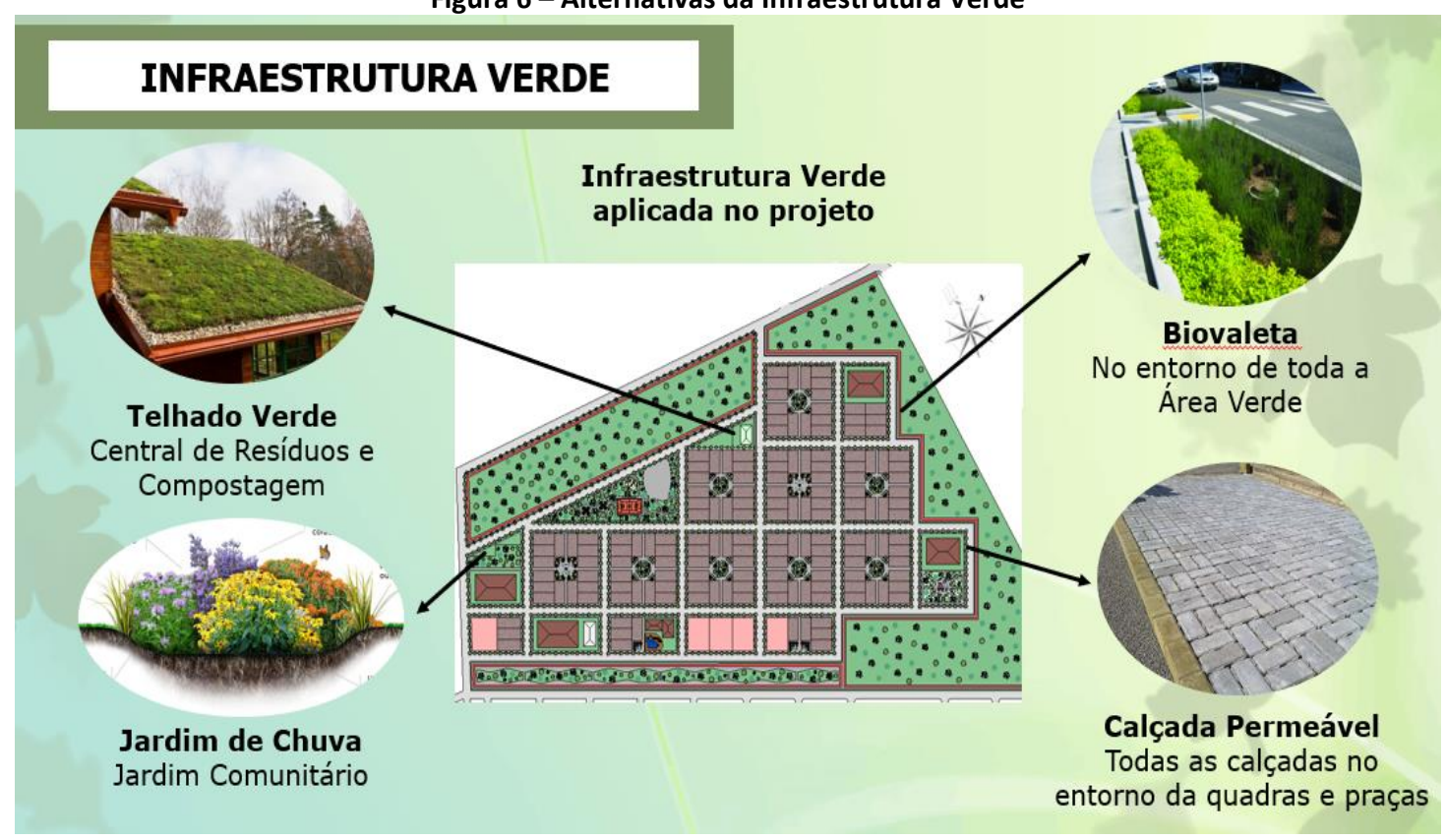

Fonte: Elaborado pela autora

No loteamento foi previsto a implantação de um telhado verde na Central de resíduos e compostagem, que serviria de protótipo e modelo para outros projetos públicos.

As Biovaletas foram previstas no entorno de toda a área verde do loteamento, o que auxilia na condução das águas pluviais até as fontes hídricas, podendo ainda propiciar o armazenamento e reaproveitamento da água para outras finalidades em todo o loteamento.

Além destes benefícios, a biovaleta também ajuda a regular o microclima da região e a melhorar a qualidade do ar, que em alguns períodos do ano é bem crítica em nossa região.

Os jardins de chuva estão presentes no jardim comunitário, o que confere ao bairro uma melhora estética e podem ser cultivados pelos próprios moradores com baixo custo tanto de implantação como de manutenção.

Foram implantadas calçadas permeáveis no entorno de todas as praças, das áreas verdes preservadas e das quadras dos lotes residenciais, comerciais e institucionais, o que auxilia no escoamento das águas pluviais, reduzindo as ilhas de calor, acúmulo de água e alagamentos. 


\begin{abstract}
A infraestrutura verde surge como um instrumento do urbanismo sustentável que pretende minimizar os impactos da urbanização sobre a natureza, tornando os espaços urbanos onde ela é aplicada mais resilientes ou menos vulneráveis, pois ela pretende conservar os valores e funções dos ecossistemas naturais e ao mesmo tempo oferecer benefícios para os seres humanos. (BRANDÃO \& CRESPO, 2016)
\end{abstract}

A infraestrutura aplicada é muito simples, porém é importante sua manutenção pelo poder público e pela sociedade, garantindo todos os seus benefícios atuais e futuros.

Para o planejamento e a setorização do loteamento foram observados alguns critérios para o uso e ocupação do solo no município de Cuiabá, conforme a Lei Complementar n 389/2015 ${ }^{4}$, em seu Art. 108.

Da área total de $212.109,23 \mathrm{~m} 2$, foram reservadas $11,34 \%$ para áreas livres de uso público ${ }^{5}$, sendo $10 \%$ o exigido na Lei Complementar $n^{\circ} 389 / 2015$. Para compor esta área foram projetadas uma praça longa, uma praça triangular com quadra poliesportiva, uma praça com academia ao ar livre, nove praças no centro das quadras residenciais, um jardim comunitário, uma horta comunitária e um pomar comunitário.

Foram reservadas 5,12\% para áreas institucionais/equipamentos públicos comunitários, sendo exigidos $5 \%$ em lei, onde algumas áreas foram reservadas para a instalação de uma creche, um centro comunitário, uma central de resíduos e compostagem, uma escola, um posto de saúde e um centro de convivência para idosos.

Para o sistema de circulação viária foram reservados $26,49 \%$, incluindo as vias de circulação de carro e as calçadas para circulação de pedestres, sendo exigidos $10 \%$ em legislação.

Além destas áreas que são exigidas por lei, foram reservados $28,03 \%$ da área, onde a vegetação já existente e mais densa foi preservada, além de $3,83 \%$ para a instalação de ciclovias, o que totalizou 3000 metros linear.

Para os lotes residenciais foram destinados $22,96 \%$ da área total do loteamento, sendo possível a implantação de 159 lotes de $12 \times 25 \mathrm{~m}\left(300 \mathrm{~m}^{2}\right)$ e 3 lotes de $15 \times 28\left(336 \mathrm{~m}^{2}\right)$, lotes bem maiores do que o tamanho mínimo de $125 \mathrm{~m}^{2}$, estabelecido na Lei Complementar $\mathrm{n}^{\circ}$ $389 / 2015$, o que proporciona maior flexibilidade na construção das residências e maior conforto as famílias beneficiadas.

Foram disponibilizados 2,24\% para os lotes comerciais, totalizando cinco lotes com áreas de 900 à $1100 \mathrm{~m}^{2}$ cada.

Na Figura 5 é apresentada a proposta desenvolvida para o Ecobairro em diversos setores, os quais serão representados a partir de cores e uma sequência numérica, onde foram previstos os seguintes setores: área verde preservada, praças, áreas institucionais, lotes residenciais, lotes comerciais, horta comunitária, jardim comunitário, pomar comunitário e ciclovia.

\footnotetext{
${ }^{4}$ Lei complementar no 389, de 03 de novembro de 2015. Disciplina o Uso e Ocupação do Solo no município de Cuiabá.

${ }^{5}$ Lei complementar no 389, de 03 de novembro de 2015, VII-ÁREA LIVRE DE USO PÚBLICO: área de uso comum do povo, destinada à implantação de praças e parques públicos, também denominada de espaço livre, sistema de lazer ou praça, com, pelo menos, 50\% (cinquenta por cento) de sua área total com vegetação arbórea.
} 


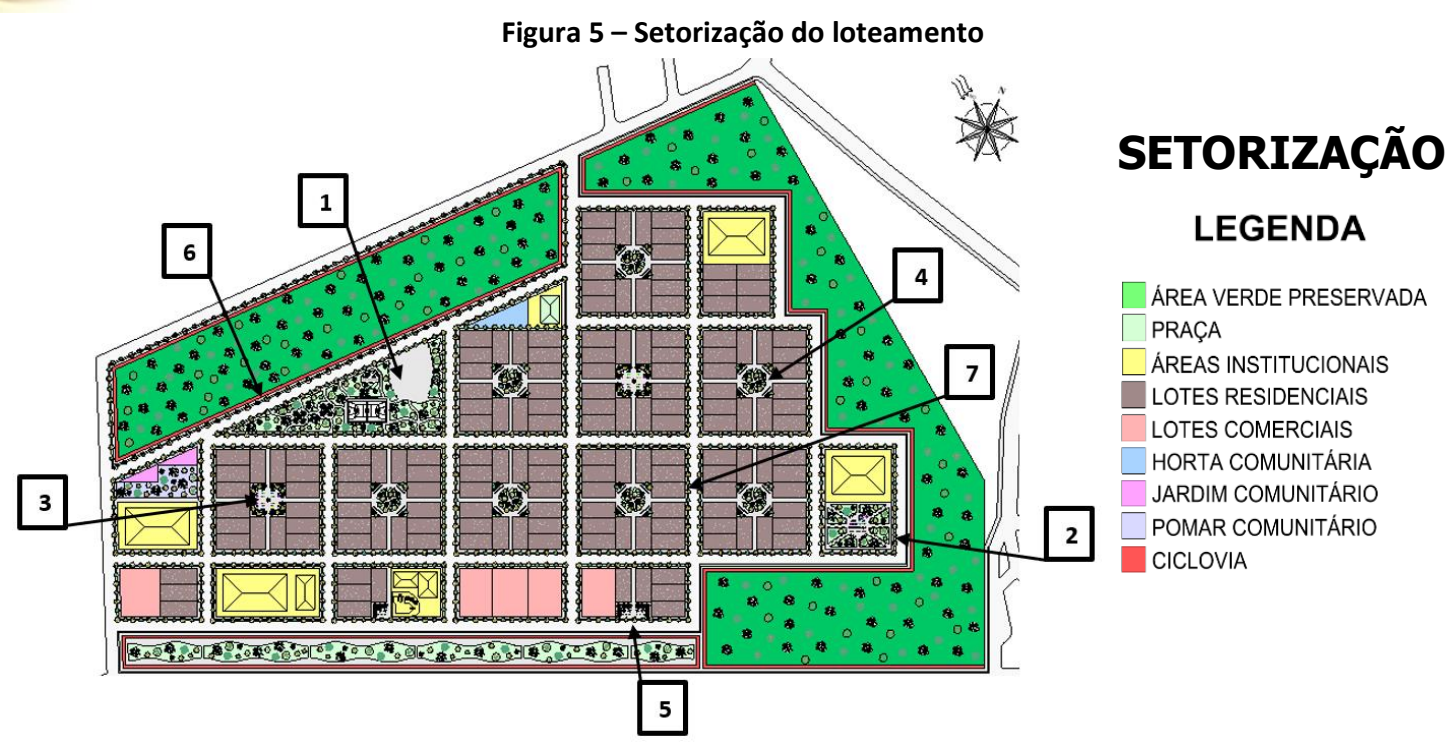

Fonte: Elaborado pela autora

O loteamento possui várias praças, dentre elas há uma maior, com formato triangular e bem arborizada, com uma quadra poliesportiva, um playground e um espaço para eventos.

Na Figura 6 está o detalhamento da praça e algumas perspectivas, esta praça além de proporcionar uma boa estética para o bairro, também é um local de lazer, cultura e interação social.

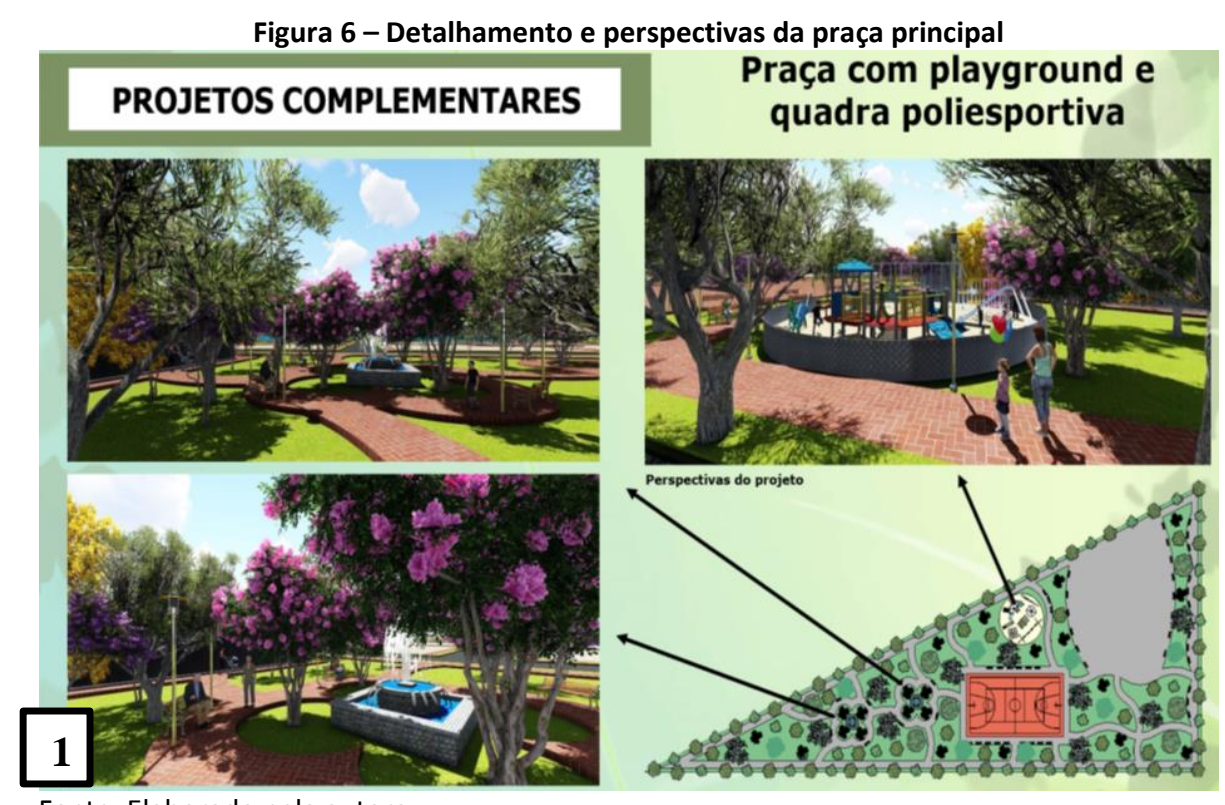

Fonte: Elaborado pela autora

Ao lado do centro comunitário foi projetada uma praça com academia ao ar livre (Figura 7), sendo uma área bem arborizada, proporcionando sombreamento para os usuários, além de bancos para o descanso dos mesmos. 


\section{Periódica Eletrônica}

\section{Fórum Ambiental}

Volume 14, Número 2, 2018

da Alta Paulista

ISSN 1980-0827

Figura 7 - Detalhamento e perspectivas da praça com academia ao ar livre

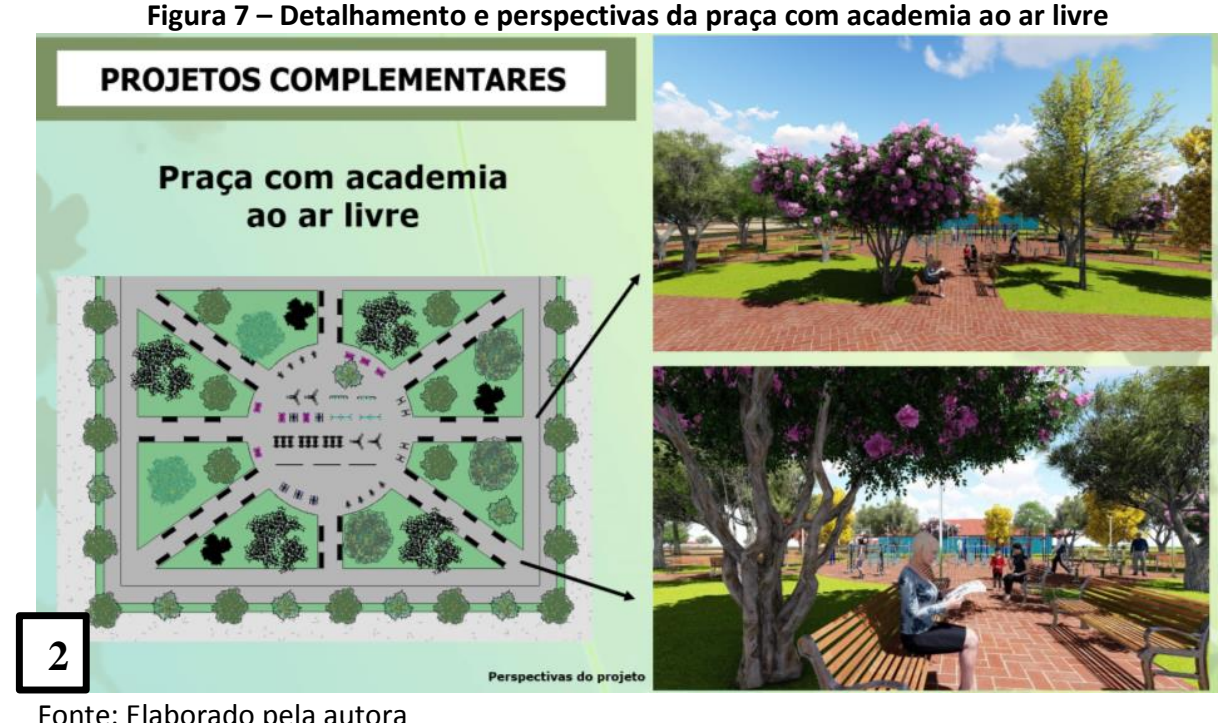

No centro das quadras dos lotes residenciais foram projetados dois tipos de praças, uma mais funcional e esportiva e outra mais voltada para repouso.

Na Figura 8 podemos ver uma das praças que estão localizadas no centro das quadras, com academia ao ar livre, um espaço mais próximo aos moradores, podendo ser utilizado por todos para suas atividades físicas.

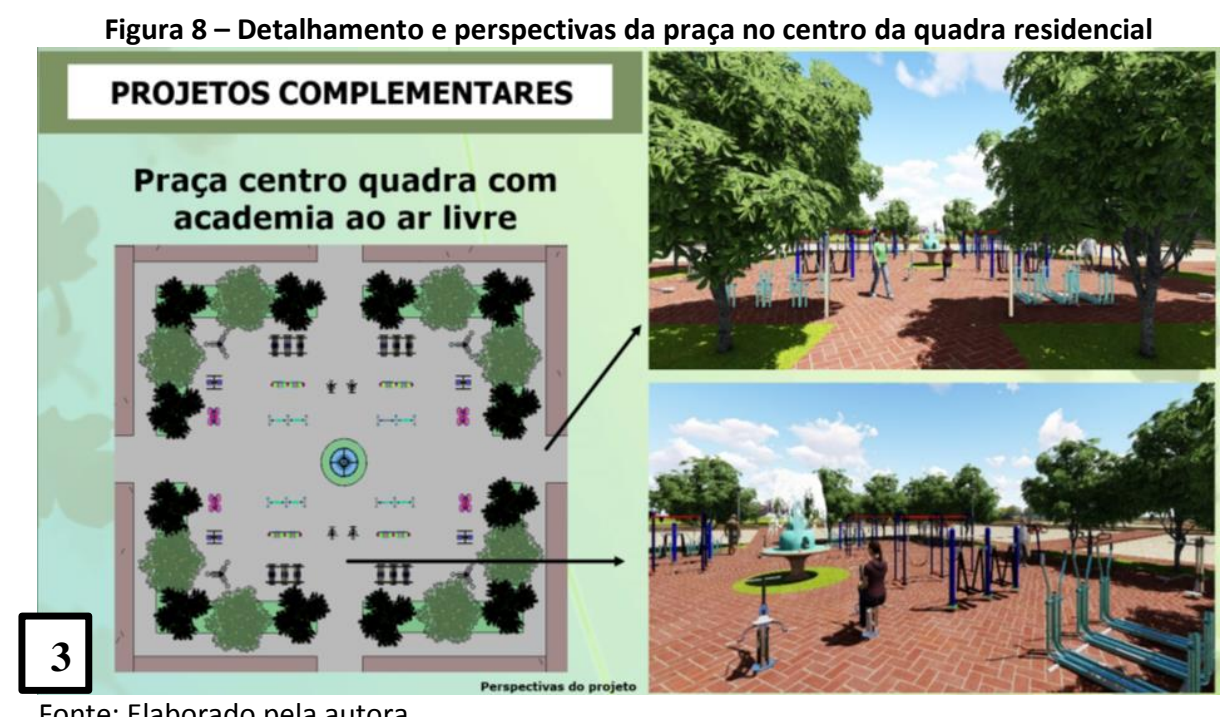

Na Figura 9 temos o outro modelo de praça no centro das quadras residenciais, um local bem arborizado com bancos para descanso e interação social entre os moradores. 


\section{Periódica Eletrônica}

\section{Fórum Ambiental}

Volume 14, Número 2, 2018

\section{da Alta Paulista}

ISSN 1980-0827

Figura 9 - Detalhamento e perspectivas da praça no centro da quadra residencial

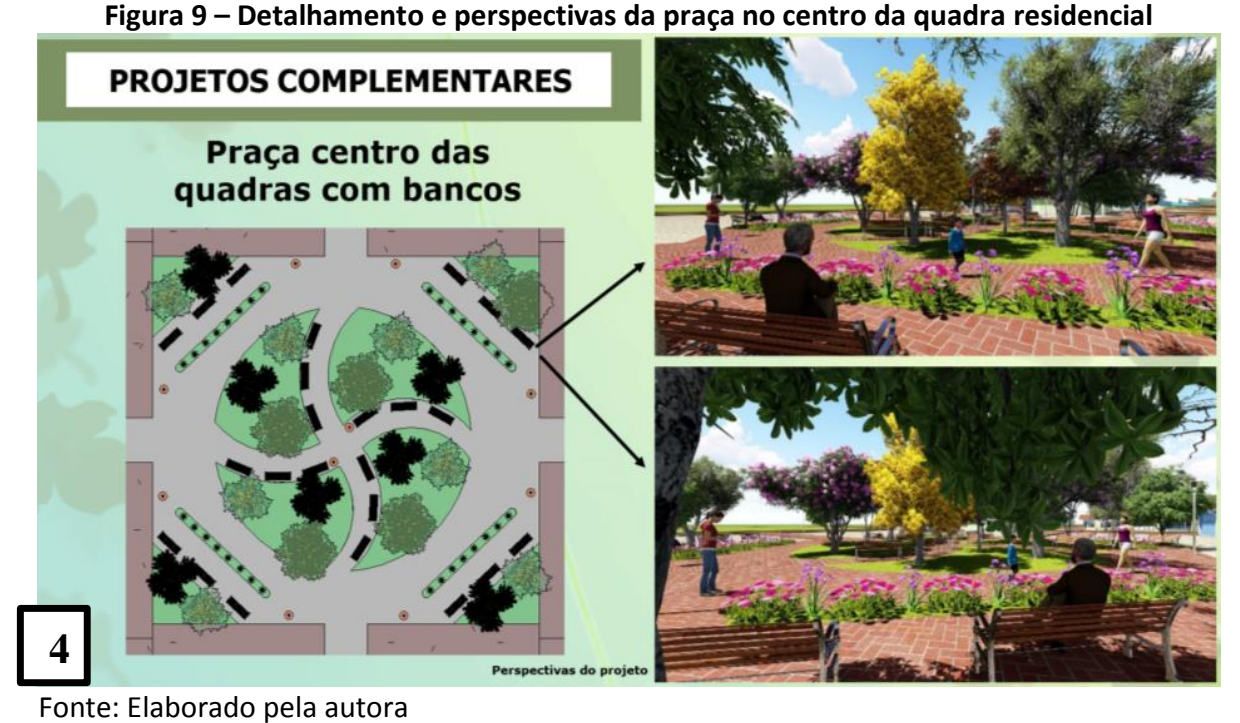

Várias praças foram projetadas para tentar suprir uma deficiência da região que não dispõe de espaços semelhantes. Elas proporcionam mais espaços de lazer, esporte e atividades diversas, melhorando a relação entre os moradores, diminuindo a desigualdade social e proporcionando espaços de entretenimento para as crianças, jovens e adultos.

Um espaço com arborização, mesas e cadeiras para jogos foi projetado para oferecer aos moradores um local para a prática de jogos e estudo (Figura 10).

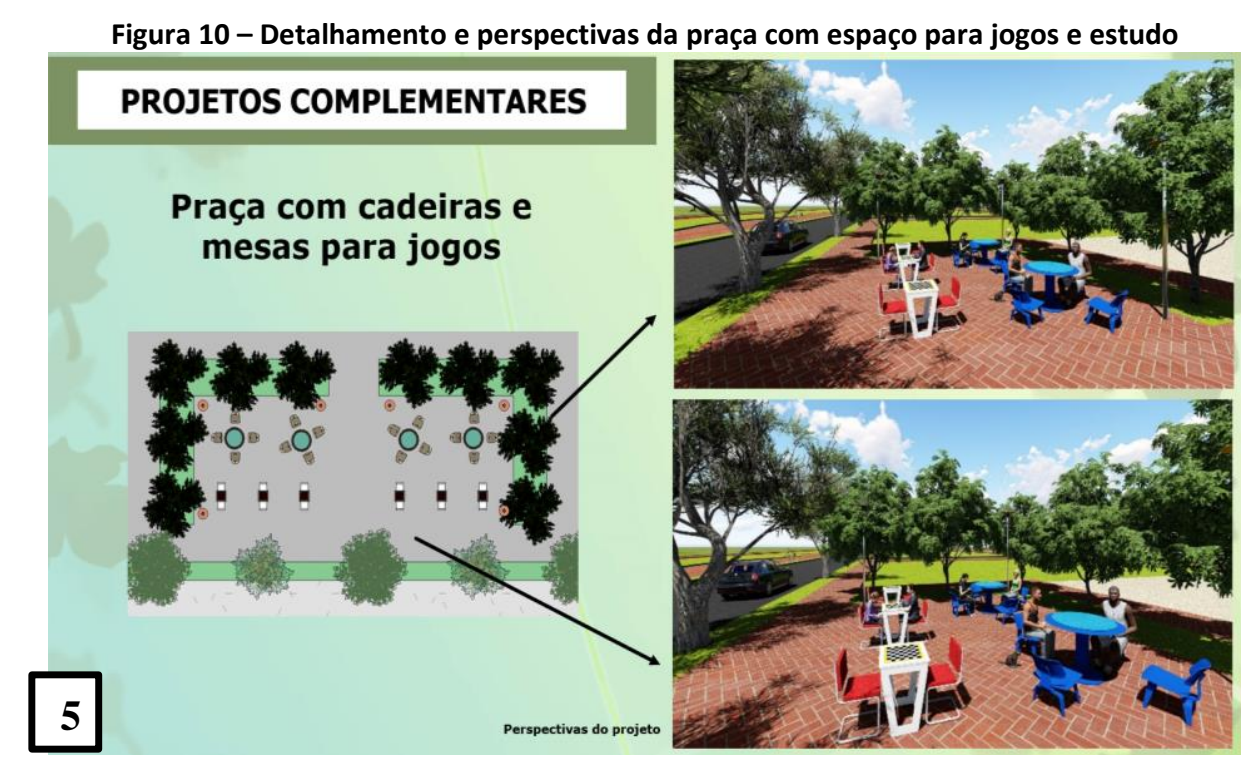

Fonte: Elaborado pela autora

A ciclovia (Figura 11) foi projetada em todo o entorno da área verde preservada e no entorno de uma das praças, totalizando $3.000 \mathrm{~m}$ linear de pista bidirecional de $2,40 \mathrm{~m}$ de largura, o que permite o cruzamento de um ciclista com o outro com maior segurança. 


\section{Periódica Eletrônica}

\section{Fórum Ambiental}

Volume 14, Número 2, 2018

da Alta Paulista

ISSN 1980-0827

Figura 11 - Detalhamento e perspectivas da ciclovia

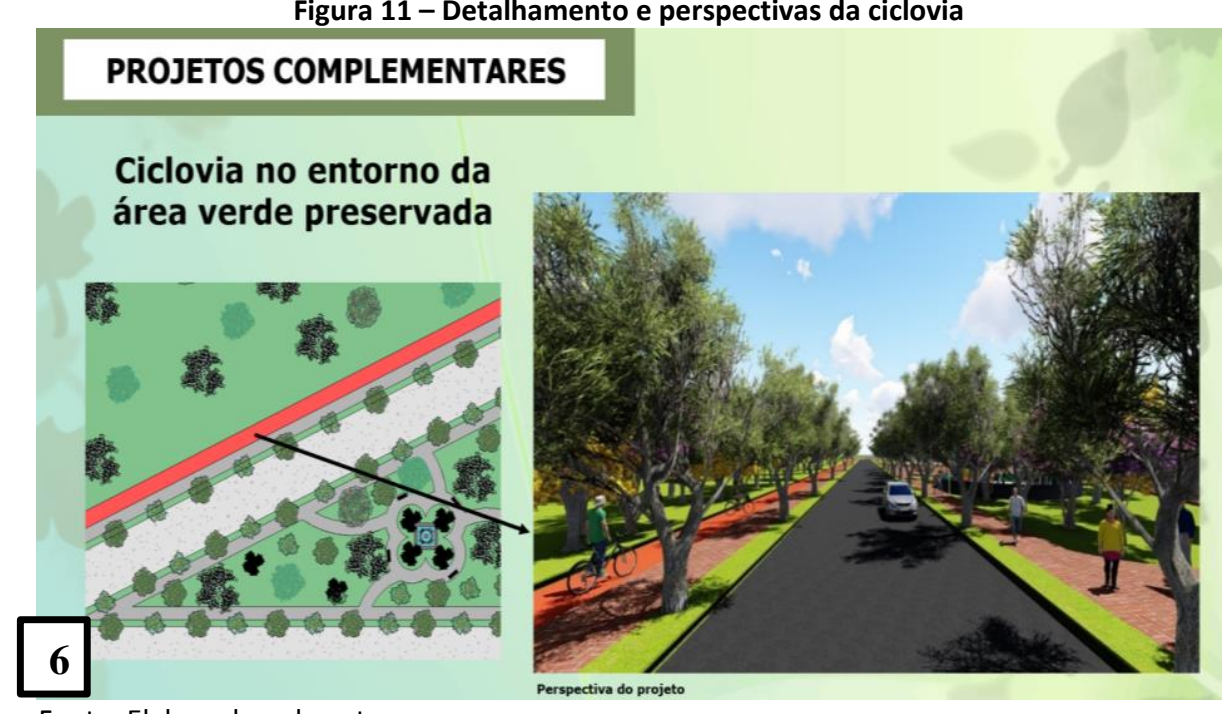

Fonte: Elaborado pela autora

As ciclovias são vias alternativas para o deslocamento dos moradores pelo bairro, para a escola ou trabalho, e são importantes, pois além de diminuir a circulação de carros e consequentemente a poluição atmosférica, são locais adequados para lazer e esporte, beneficiando a saúde dos usuários.

As calçadas foram projetadas com 3,00m de largura para proporcionar maior conforto aos pedestres, sendo $2,00 \mathrm{~m}$ para circulação de pedestres e $1,00 \mathrm{~m}$ de área vegetada com árvores para sombreamento.

Na Figura 12 temos uma perspectiva das calçadas vegetadas com grande sombreamento para os pedestres e para os veículos, o que melhora muito a qualidade do ar e a qualidade de vida dos moradores.

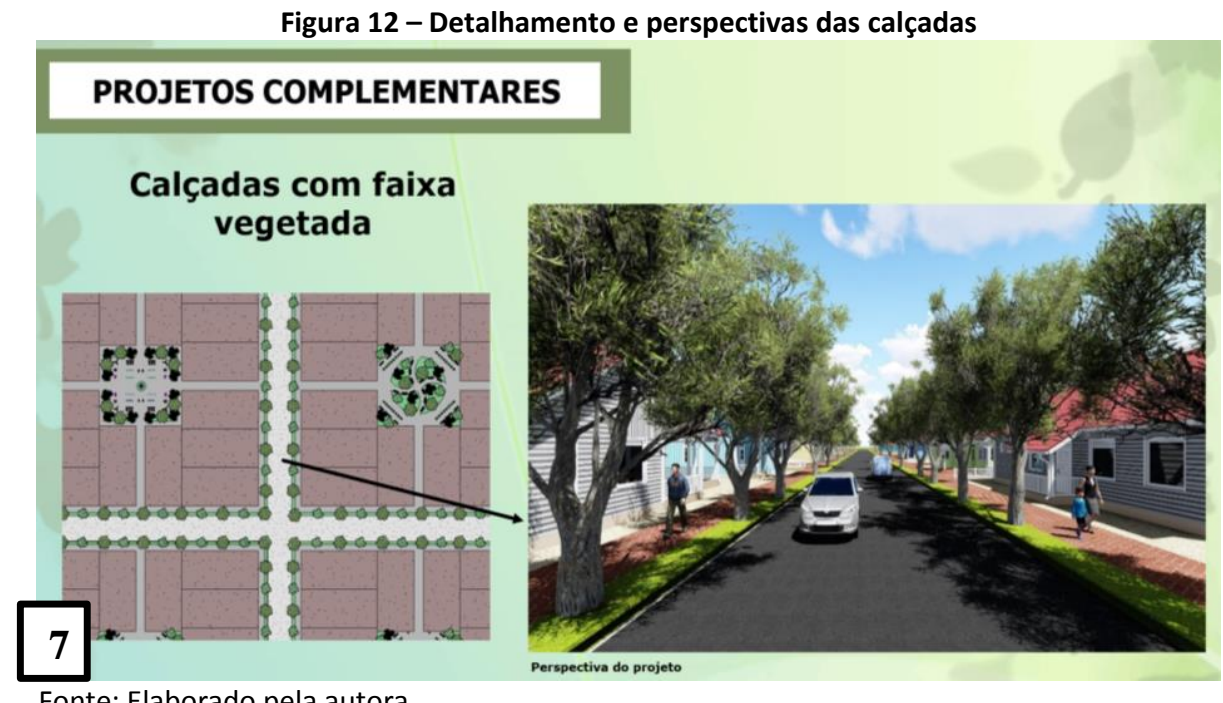

A mobilidade dentro do bairro, principalmente do pedestre, é favorecida com a presença de calçadas largas e sombreamento adequado. 


\title{
Periódica Eletrônica
}

\section{Fórum Ambiental}

Volume 14, Número 2, 2018

ISSN 1980-0827

\author{
da Alta Paulista
}

\section{CONSIDERAÇÕES FINAIS}

A implantação de Ecobairros é de suma importância para a melhoria de vida das pessoas e sem dúvida para a melhoria das cidades e meio ambiente.

As cidades precisam urgentemente de atenção do poder público, pois estão saturadas de problemas de infraestrutura e sociais, que muitas vezes são decorrentes da falta de planejamento adequado na criação de novos bairros e cidades.

Muitos loteamentos surgem de forma clandestina e vão crescendo até o ponto de não ser mais possível intervenções que garantam a qualidade de vida dos moradores, por isso a importância de cuidar das cidades e criar bairros e loteamentos planejados, com princípios da sustentabilidade e infraestrutura verde, buscando uma relação harmônica entre o meio ambiente, urbano e social.

A criação de projetos urbanos que sirvam de modelo para futuras implementações pelo poder público é primordial, pois hoje ainda são poucos os bons exemplos de obras públicas como estas inseridas nas cidades.

A perfeita interação do meio ambiente com o meio urbano é primordial, pois o ambiente natural é essencial para nossa existência, e é através de bons projetos urbanos que conseguiremos melhorar esta relação.

\section{REFERÊNCIAS BIBLIOGRÁFICAS}

ANDRADE, Liza M. S. de A.; ROMERO, Adriana B.. Desenho de Assentamentos Urbanos Sustentáveis: Proposta Metodológica. São Paulo: claCS'04 e ENTAC'04, 2004.

AZEVEDO, Hugo M. Projetos Urbanos Sustentáveis Segundo a Abordagem dos Ecobairros. Rio de Janeiro: Escola Politécnica, Universidade Federal do Rio de Janeiro, 2015.

BRANDÃO, Fernanda C. A. dos S.; CRESPO, Henrique de A.. Diretrizes Relacionadas à Implantação da Infraestrutura Verde para Aumentar a Resiliência Urbana às Mudanças Climáticas. Rio de Janeiro: UFRJ/Escola Politécnica, 2016.

BRASIL. Lei no 6766, de 19 de dezembro de 1979. Dispõe sobre o parcelamento do Solo Urbano. Edição federal, Brasília-DF, 1979;

BRASIL. Plano Nacional de Saneamento Básico - PLANSAB. Ministério das Cidades Secretaria Nacional de Saneamento Ambiental. Brasília-DF, 2013.

CUIABÁ. Lei Complementar no 150, de 29 de janeiro de 2007. Dispõe sobre o Plano Diretor de Desenvolvimento Estratégico de Cuiabá. Edição Municipal, Cuiabá-MT, 2007;

CUIABÁ. Lei Complementar no 389, de 03 de novembro de 2015. Disciplina o Uso e Ocupação do Solo no município de Cuiabá. Edição Municipal, Cuiabá-MT, 2015;

CUIABÁ. Perfil socioeconômico de Cuiabá, volume V. Cuiabá, MT: Central de Texto, 2012.

GATTI, Simone. Espaços Públicos. Diagnóstico e metodologia de projeto. Coordenação do Programa Soluções para Cidades. São Paulo: ABCP, 2013.

GONDIM, Monica Fiuza. Cadernos de Desenhos Ciclovias. ISBN: 978-85-906631-1-9. 2010. 